\title{
THE INCLUSION OF PREFIXAL MATERIAL IN ZULU REDUPLICATION
}

\author{
Toni Cook \\ University of Vermont
}

\begin{abstract}
The aim of this paper is twofold: to introduce new data that show reduplication in Zulu admits inflectional morphemes to the left of the verb stem rather than within the stem on the right, and to give an analysis of Zulu reduplication that does not require access to underlying morphosyntactic structure. Instead, reduplication is a template-filling copying operation that interacts with linear phonological structures and does not target morphosyntactic objects. The data presented here argue for an analysis in which the crucial distinction is between morphemes within the scope of reduplication and those outside it; the left/right asymmetry in the appearance of inflectional morphemes in the reduplicant is attributable to a process of Local Dislocation (Embick 2007). Reduplication is treated as a copying operation that has indirect access only to morphosyntactic structure through phonological operations. Consequently, reified subconstituents of the verb complex, such as the Macrostem (Hyman, Inkelas, and Sibanda 2009), are not accessible as such to the process of reduplication. However, data from VCV stems show that morphosyntactic structure affects reduplication in certain constructions. Tonal data is used to show that the "prefixal" affiliation of prefixal morphemes is voided if these morphemes are reduplicated. ${ }^{1}$
\end{abstract}

Keywords: Zulu, morphosyntax, reduplication

\section{Introduction}

In Zulu, reduplication consists of a disyllabic constituent prefixed to the verb stem. It is described in Doke (1927:1992) and Downing (2009), and the process in mutually intelligible Ndebele is discussed in Downing (2001a), Sibanda (2004) and Hyman, Inkelas, and Sibanda ((2009), henceforth Hyman et al.). The meaning of reduplication is the familiar semantics of performing the action denoted by the verb without skill, or intermittently. When the verb root is minimally CVC, the reduplicant (RED) begins with the first segment of the root (1). However this paper will focus on cases in which the root is sub-minimal, with a prosodic shape of C or VC (like -dl- 'eat', -m- 'stand', -f- 'die', or -enz- 'do, make', -akh- 'build', -eb- 'steal'). The RED+base complex is bracketed, with RED on the left and the base on the right (unless noted otherwise, tone marked is underlying):

1 Thanks to Thobile Ngcobo, Sandile Khumalo, and Sebenzile Khanyile for generously sharing their language with me, and providing the judgments cited here, and to Larry Hyman and Dave Embick for generous feedback on this work. I am grateful as well to the anonymous reviewers whose comments helped me to clarify my arguments and improve the organization of the paper. Any remaining errors or omissions are my own. 

(1) a. u-fúnd-a 'you study' $\rightarrow$ u-[fúnd-a+fund-a] 'you do a bad job studying'2 2SG-study-FV
b. ngi-phek-a 'I cook' $\rightarrow$ ngi-[phek-a+phek-a] 'I do a bad job cooking' $1 \mathrm{SG}-\mathrm{cook}-\mathrm{FV}$
c. bá-sébenz-a 'they work' $\rightarrow$ bá-[sébe+sebenz-a] 'they do a bad job working' 3PL-work-FV

Since sub-minimal roots are, by definition, smaller than CVC, the root will need to be augmented somehow to satisfy the disyllabicity requirement exerted on RED. For a verb complex consisting solely of a subject marker, root, and a final vowel, a consonantal sub-minimal root like -dl- will be augmented with the empty morpheme -yi-:
(2) a. u-dl-á $\quad$ 'you eat' $\rightarrow$ u-[dl-á-yi+dl-a]
2SG-eat-FV
b. si-mb-a 'we dig' $\rightarrow$ si-[mb-a-yi+mb-a]
1PL-dig-FV
c. bá-m-á 'they stand' $\rightarrow$ bá-[m-á-yi+m-a]
3PL-stand-FV

Hyman et al. show that for mutually intelligible Ndebele, the object marker (OM), which, if present, always occurs immediately to the left of the root, can be included in reduplications of subminimal roots (Hyman et al. (31), p.12). The reduplication including the $\mathrm{OM}$ is grammatical along with the -yi- version shown in (2) above, and the examples in (3) are grammatical for both Zulu and Ndebele.

(3) a. u-ya-zí-dl-á 'you eat them' (cl. 10)

2SG-LF.PRES-OM10-eat-FV

b. ngi-ya-sí-mb-a 'I dig it' (cl. 7)

1SG-LF.PRES-OM7-dig-FV

c. si-ya-wá-ph-á 'we give them' (cl. 6)

1PL-LF.PRES-OM6-give-FV

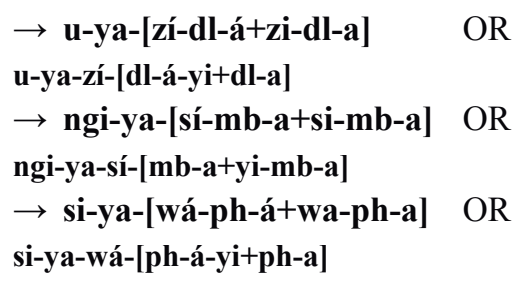

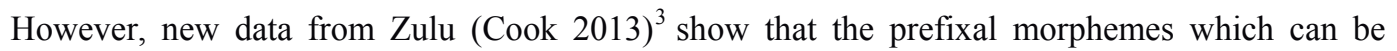
included in RED are not limited to the object marker alone. Significantly, morphemes like the long form present marker -ya-, durative -sá-, and infinitival -ku- are allowed to appear in RED as well (4a-d). Crucially however, a syllabic subject marker is not allowed to reduplicate (4e). ${ }^{4}$

2 The tone of the verb root surfaces on the final vowel because the consonantal root -dl- lacks a TBU on which its high tone can surface.

3 Cook (2013) provides a more extensive account of the patterns found in Zulu reduplication; the relevant data are fully discussed in this paper.

4 A reviewer raised the question of the prefixal remote past marker -aa-; this morpheme cannot reduplicate, presumably because of the long vowel. 
(4)
a. u-ya-dl-á 'you eat'
2SG-LF.PRES-eat-FV
b. bá-ya-mb-a 'they dig'
3SG-LF.PRES-dig-FV
c. ni-sá-f-á 'you (pl.) still die'
2PL-DUR-die-FV
d. ú-ku-sh-á 'to burn'
AUG-INF-burn-FV
e. ni-dl-á 'you (pl.) die....'
2PL-die-FV

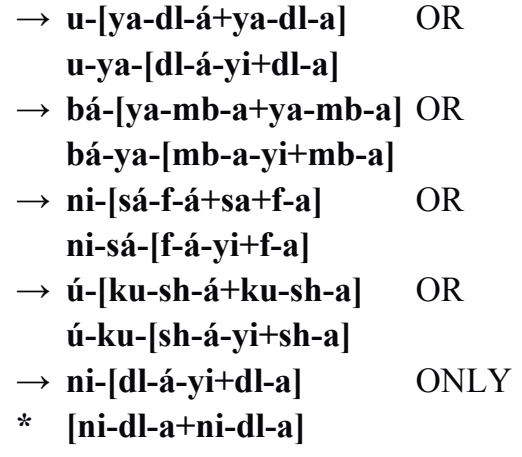

These morphemes occur to the left of the OM, and cannot appear in RED if an object marker is present; that is, reduplication always respects the linear order of morphemes, and cannot skip intervening elements:

$$
\text { u-ya-zí-dl-á 'you eat them (cl. 10) }
$$$$
\rightarrow * \mathbf{u}-\mathbf{z i}-[\mathbf{y a}-\mathbf{d l}-\mathbf{a}+\mathbf{y a - d l - a}]
$$

The finding that prefixal morphemes to the left of the object marker are available for reduplication is an important one, because it calls into question the nature of the constituents that are accessible to reduplication, and whether these constituents are best understood morphosyntactically or phonologically.

That is, if object markers were privileged in being the sole prefixal morphemes permitted to reduplicate, it would be necessary to consider them as a class apart, as special somehow within the prefixal domain. However, the new data from Zulu argue that what matters is being left-adjacent to the root, and that many morphemes appearing in this position reduplicate, not object markers alone. What is relevant for reduplication is not the morphosyntactic status of the object marker, but the phonological position of left-adjacent to the root. As the example in (4e) shows, simply being left-adjacent does not mean a morpheme can reduplicate; a syllabic morpheme cannot reduplicate if it is the first morpheme in the verb complex.

\section{Morphosyntactic structure of the Zulu/Ndebele verb}

In their important and influential paper on reduplication in Ndebele, Hyman et al. employ the Morphosyntactic Doubling Theory articulated in Inkelas and Zoll (2005), and argue that the patterns attested in Ndebele are a matter of correspondence between two underlying structures (traditionally called the reduplicant and the base). Their claim is that reduplication manipulates morphosyntactic structures, and then gives these structures phonological content. The approach implemented here dispenses with the morphosyntactic component, and only allows reduplication access to structures that have already been phonologized as linear strings with segmental content.

Hyman et al.'s analysis is greatly influenced by Downing's work on Bantu reduplication, specifically in Kinande (2000), Ndebele (2001a), Swati (1997, 1999), and Xhosa (1998). The crux of Downing's Optimality Theory argument is that in all these languages, the reduplicant is a "canonical verb stem" (2000, p. 2); her argument would be easily extended to include Zulu as well. Significantly, a canonical verb stem is a morphological entity (indeed it is identified by Downing as such), and the content of the reduplicant interacts extensively with both 
morphosyntax and phonology. For instance, the reduplicant is constrained to be disyllabic (phonology), but is also constrained to not include material from the "Inflectional Final Suffix" (morphosyntax). The Distributed Morphology approach implemented here seeks to locate reduplication exclusively in the phonology, and prevent extensive (and often redundant) interleaving of morphology and phonology.

This paper shows that a more phonologically oriented process, specifically copying to a prosodic template, provides better coverage of the facts in light of the inclusion of prefixal morphemes outside of the object marker. Hyman et al.'s argument crucially depends on the reduplicant being co-extensive with a morphosyntactic object, and data like those presented in (4) serve as evidence that reduplication directly interacts with phonological representations, and does not manipulate, nor have access to, morphosyntactic structure.

Downing (1997) presents evidence that the reduplicant in Swati (an Nguni language mutually intelligible with Ndebele and Zulu), is constrained to include material exclusively from the extended root (Odden 1996), (Figure 1 below), the portion of the verb complex that consists of the root plus any extension suffixes that may be present, such as the causative -is- or applicative -el-. The evidence Downing puts forward to support this analysis comes largely from fully syllabic roots like -fund- 'study' (these data, and their analysis within the copying/Distributed Morphology framework proposed here, is presented in Sections 3 and 4). Hyman et al. use Downing's constituency in their implementation of Morphosyntactic Doubling to account for the facts from Ndebele reduplication of sub-minimal roots.

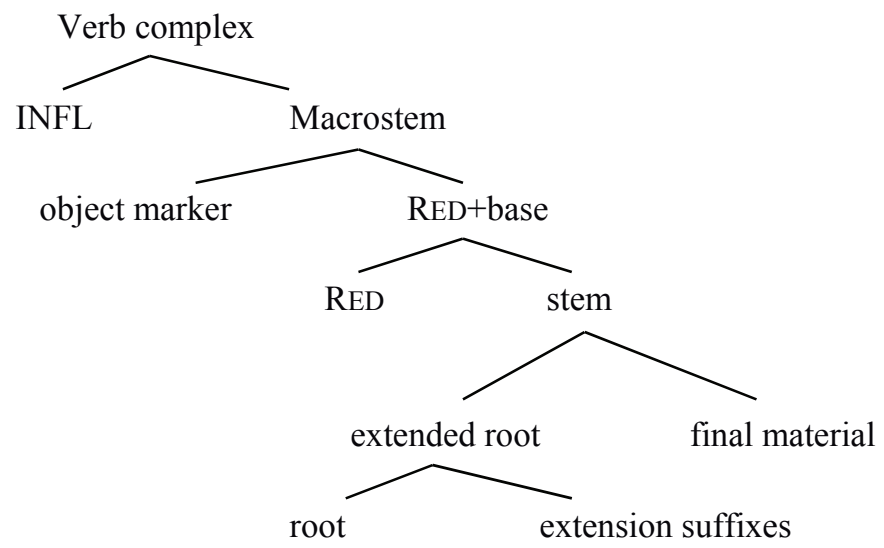

Figure 1. Morphosyntactic Constituency/Structure in the Zulu/Ndebele verb (from Downing 2001a: 35 (Hyman and Mtenje 1999, Myers 1987))

One of the keys to the connection between Downing's structure and Hyman et al.'s analysis is the Macrostem, the constituent that consists of the object marker and the stem (Kisseberth (1984) first proposed the constituent based on tonal phenomena in Digo). The Macrostem constituent exists in any verb complex containing an object marker. The Macrostem is the portion of the verb complex that begins with the object marker and extends rightward to the end of the verb complex, it is underlined in the examples below: 
(6)
a. u-ya-sí-théng-a
b. u-sí-théng-il-e
c. si-ya-kú-thánd-a
d. si-kú-thand-il-e

\author{
'You are buying it (cl. 7)' \\ 'You bought it (cl. 7)' \\ 'We love you (sg.)' \\ 'We loved you (sg.)'
}

Significantly, the Macrostem is designated as part of a hierarchical, binary structure - a sub-part of the full verb complex whose internal structure is shown Figure 1. What this figure shows is that the Macrostem is designated as a morphosyntactic constituent that neatly matches with a portion of the morphosyntactic structure of the full verb complex, i.e. everything below prefixal INFL material.

2.1 The role of the Macrostem in Hyman et al.'s analysis. The significance of the object markers being available for reduplication in Ndebele (shown in (3)), is used by Hyman et al. to support the idea that reduplication interacts with morphosyntactic structure, for the precise reason that the Macrostem is represented as a morphosyntactic unit in Figure 1. In (3) for the examples including the object marker, Hyman et al. argue the morphosyntactic object being targeted is the Macrostem. The existence of a Macrostem node in the morphosyntactic structure posited by Downing allows Hyman et al. to assert morphosyntactic doubling for reduplications that include an object marker.

The figure shows that the object marker has been given special status over the other prefixal morphemes, which are collectively lumped under an INFL node (Myers 1998). As used in the Bantuist literature, this single INFL node is not intended to indicate that there is no order among the non-object marker morphemes that occur in the prefixal domain, but rather that they constitute a class apart from the object marker. The reduplication data from Zulu challenge this constituency-although there are tonal phenomena that support the existence of the Macrostem as a meaningful domain, it is not at all clear that this structure is recognized as such by reduplication.

More specifically, the notion of morphosyntactic doubling is challenged by examples such as (4). The data presented here argue that the object marker is simply the most likely prefixal morpheme to reduplicate because it is closest to the root, and not due to any "qualitative" distinction between object markers and other prefixal morphemes. The finding that prefixal morphemes outside (to the left) of the Macrostem can participate in reduplication is an important one because it presents a counterpoint to the argument put forward in Hyman et al. that reduplication is a matter of morphosyntactic matching.

Unlike the Macrostem that consists of the $\mathrm{OM}+$ stem, there are no pre-established constituents that correspond to $\mathbf{y a}+$ stem or $\mathbf{s a}+$ stem. This finding leads to the conclusion that reduplication in Zulu is best analyzed as a process that interacts with phonological constituents-namely for subminimals, the root plus one syllable to the left- and not directly with morphosyntactic structure. ${ }^{5}$ To pursue a morphosyntactic matching analysis in light of these facts would leave us with two equally unsatisfactory options. First, one could argue that reduplication is morphosyntactic matching (of the Macrostem) when object markers are included in RED (3), but phonological copying when other prefixal morphemes are involved, as in (4). Alternatively, one could claim

\footnotetext{
5 A reviewer raises the point that "root" is in fact a morphosyntactic object, and not a phonological one. To operationalize "root" phonologically, we can understand it as the phonological output of the cycle that consists of the acategorical root node + the category-defining head (see Section 3 and Figure 2).

Similarly, it is the object that is immediately right-adjacent to the bare $[\sigma \sigma]$ reduplicative template.
} 
that $\mathbf{y a}+$ stem and sa+stem constitute morphosyntactic domains as well. Pursuing this reasoning though, we are left not only with a multiplicity of morphosyntactic domains, we also then have a morphosyntax and phonology that are perfectly isomorphic, in that everything that is a phonological constituent is a morphosyntactic constituent as well, and the systems are redundant.

\section{The copying approach to reduplication in Distributed Morphology}

In the theory of reduplication implemented here, it is treated essentially as a copying process (Marantz 1982, Rackowski 1999). The framework used is Distributed Morphology (DM) (Halle and Marantz 1993, Embick 2010), and RED is interpreted as a bare disyllabic template [ $\sigma \sigma]$ that receives segmental content from the phonological material to its right; put differently, it is a $[\sigma \sigma]$ template that also contains the instruction to copy from material to its right. Similar to Figure 1, I start off assuming an underlying structure as in Figure 2 below .

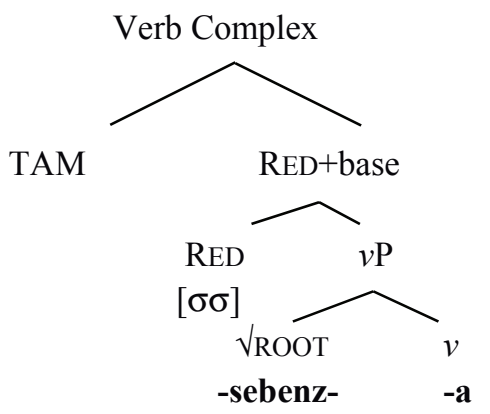

Figure 2. Schematic Distributed Morphology structure for a reduplicated verb

The point of this section is not to provide an overview of Distributed Morphology, but instead to acquaint the reader with the minimum information necessary to make sense of the argument, and to recognize how DM differs from the Morphosyntactic Doubling approach to reduplication.

In DM, roots are assumed to be acategorical, beginning the derivation neither as nouns, verbs, adjectives, etc. and must merge with a category-defining head; the verbal head $v$ takes as its complement the acategorical root -sebenz- 'work' and yields the verb -sebenz-a (the argument in favor of treating the default Bantu verbal final vowel $-a$ as the phonological realization of the verbalizing head is discussed in Section 4). Figure 2 is clearly a syntactic structure, and "spell-out" refers to the point in the derivation when this structure is sent to the phonological component of the grammar for phonological processing. Once "in" the phonology, the terminal nodes of the structure must receive their phonological content (this is referred to as Vocabulary Insertion), and the structure must be linearized before copying can take place.

It is important to note that in Distributed Morphology, syntactic operations take place on objects that have not yet received their phonological form. For instance, in Figure 2, the only phonological material that is present at the beginning of the derivation is the root morpheme -sebenz-. The $v$ head receiving the phonological form [a] and even the RED morpheme getting the phonological "content" of a bare $[\sigma \sigma]$ template are only present after Vocabulary Insertion (Harley and Noyer 1999). This point is not crucially important to the argument here, which relies on a linear, non-hierarchical object to explain reduplication, but the abstractness of 
the morphosyntactic structure assumed in Distributed Morphology is a distinguishing feature of the theory.

The analysis put forward here proposes that reduplication results from a bare disyllabic template that is filled by segmental material copied from morphemes that have already undergone phonological processing. Crucially, this processing takes place in an "inside out" direction (Bobaljik 2000), that is, more deeply/centrally embedded morphemes are sent to the phonological component prior to those that are more outer/peripheral. In the default case for reduplication, those pieces will be minimally the root and the verbalizing head, and the RED morpheme will simply contain a phonological copy of the first two syllables to its right:

(7) Spell-out and phonological operations on RED+base constituent in Fig. 2

Vocabulary insertion and linearization on $v \mathrm{P}$ :

sebenz-a

Vocabulary insertion and linearization on RED+base:

Mapping to template:

$[\sigma \sigma]-$ sebenz-a

-sebe+sebenz-a

DM takes a strictly derivational approach to the building of morphophonological objects, meaning that objects are built piece-by-piece, and all morphology and phonology are not copresent. Chiefly, there are several significant insights afforded by this approach:

- The copying process central to reduplication necessarily operates on a phonological string that lacks morphosyntactic structure or affiliation, because copying takes place subsequently to linearization.

- The optionality that is a striking feature of reduplication (shown in the examples in (3), (4)) directly follows from reduplication being able to take place at different points in the derivation; or allowing for the filling of the reduplicative template to not have an absolute fixed order in the building of the verb complex. The fact that certain verb complexes can have multiple acceptable reduplications follows directly from this assertion.

- The asymmetry between the inclusion of prefixal material to the left of the stem and yi augmentation on the right is a natural consequence of phonological processing of a linear string, and shows the action of reduplication to be rooted in the phonological component of the grammar, rather than in underlying morphosyntactic structure. Mapping occurs from the left to the right, and yi insertion occurs when the string "runs out" of phonological material to fill the template (shown in examples (14) and (15)).

\section{Inflectional material at the right edge}

This section focuses on the ungrammaticality of reduplications that include inflectional material from the right edge of the verb complex, contrasting with the earlier examples that show inflectional material from the left edge is allowed to reduplicate. Put differently, we will look at why prefixal inflectional material can reduplicate, but suffixal inflectional material cannot. The argument presented here proposes that the final -a is the phonological realization of the verbalizing head in Bantu.

All of the examples provided so far show a verb complex ending in a final vowel (FV) of -a. Most verb paradigms end with this segment; it is the Bantu "default verbal final vowel" 
(Schadeberg 2003, Mutaka and Hyman 1990), and as we have seen, in this case there is no mismatch, as the FV on RED and the base are the same:

(8) a. u-fúnd-a 'you study' $\rightarrow$ u-[fúnd-a+fund-a]

b. si-thel-a 'we pay taxes' $\rightarrow$ si-[thel-a+thel-a]

It is when the FV on the base is not -a that a mismatch occurs; regardless of the base FV, the FV on RED is required to be -a:
a. a-ngi-fúnd-i 'I don't study'
NEG-1SG-study-FV.NEG

b. ni-fúnd-e

'You (pl) study (subjunctive)'

2PL-study-FV.SBJ

$$
\begin{aligned}
& \rightarrow \text { a-ngi-[fúnd-a+fund-i] } \\
& * \text { a-ngi-[fund-i+fund-i] } \\
& \rightarrow \text { ni-[fúnd-a+fund-e] } \\
& * \text { ni-[fund-e+fund-e] }
\end{aligned}
$$

In Hyman et al.'s analysis, the final vowels marking negation and subjunctive are barred from appearing on RED simply because they are "inflectional", and carry this designation, which is assigned violations (Downing 1997, 2001a, Hyman et al.).

In the analysis articulated here, it is because the non-default FVs (like the -i of negation or the subjunctive -e) have not undergone Vocabulary Insertion at the point reduplication takes place because they are outside the scope of RED (Cook 2013). That is, they have not undergone phonological processing at the point that the RED template receives segmental content. The default $\mathbf{- a}$ is analyzed as the phonological realization of the category-defining verbalizing $v$ head. Aside from the non-a final vowels like -e and -i, nearly all "inflectional" material is present in the prestem domain (Myers 1987, 1998; Hyman 2007). Given the semantics of reduplication, it is shown as an aspectual projection in the figure below, though the only distinction between depicting it as an AspP/Asp ${ }^{0}$ vs. RED+base/RED is in the labeling, without any real implications for the analysis.

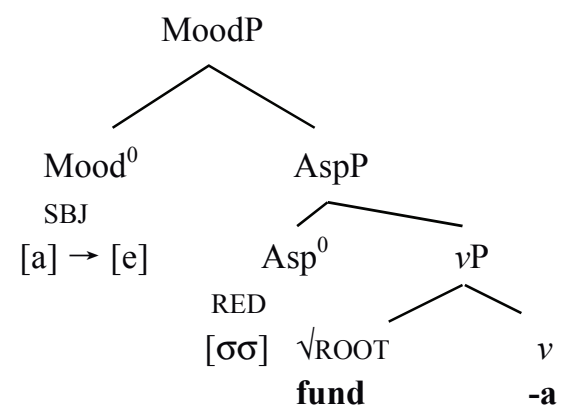

Figure 3. Default verbal FV -a as $v$ head $^{6}$

6 Following DM convention, the nodes in Figure 3 bear syntactic, rather than morphological labels. 
(10) Spell-Out and phonological (PF-branch) operations on Figure 3

$v \mathrm{P}$ Vocabulary insertion and linearization:

fund-a

AspP Vocabulary insertion and linearization:

Mapping to template:

$[\sigma \sigma]-f u n d-a$

funda+fund-a

MoodP Vocabulary insertion and linearization:

funda+fund-e

When the subjunctive morpheme undergoes phonological processing, a rule is triggered that changes the final -a on the full RED+base complex to -e (the -a is "overwritten" using the terminology of Buell (2005), p.102). Since the -a on RED is phonologically embedded within the verb complex, and RED is simply a phonological string without any morphosyntactic structure, it cannot be targeted by the [a] $\rightarrow$ [e] rule of the subjunctive. In keeping with Bobaljik (2000) and Embick (2015), phonological processing works from the inside out. This "inside-out" principle means the phonological object that consists of the reduplicated verb [funda+funda] only has one final vowel that can be subject to the [a] $\rightarrow$ [e] rule of the subjunctive, and this is the rightmost final vowel, the -a on the base. The -a on the reduplicant is phonologically embedded, or more simply, stuck in the middle of a segmental string, and inaccessible and unrecognizable as a target of the subjunctive vowel change.

Essentially, it is not surprising that the exponents of the higher TAM morphemes are realized on the base and not on RED, because the RED+base relationship is no longer accessible once the reduplicative template has been filled. The final vowel mismatch is not a mismatch between the reduplicant and the base, but instead between the reduplicant and the RED+base complex as a whole.

The intuition behind Figures (2) and (3), is that there is a bracketing problem with the structure in Figure (1), and it is thrown into relief by reduplication. The conflict lies between the pre-stem location of the morphemes affecting the quality of the final vowel (namely this chunk of INFL material in (1)), and the inclusion of the final vowel in the stem domain. By positing a low -a, not only do we resolve this tension between the pre-stem and stem domains in Figure (1), but we have an explanation for the -a observed in reduplication.

\section{Reduplication of prefixal material in Zulu and Ndebele}

In this section, we will focus on how the DM-copying analysis accounts for the reduplication patterns seen with sub-minimal consonantal roots, like -dl- 'eat', -lw- 'fight', -ph- 'give', etc. The variation between reduplications containing the empty augmentative morpheme -yi- and those containing a prefixal morpheme is argued to stem from the point in the derivation at which copying to the template occurs. The reduplicative template becomes misaligned with the root via a process known as Local Dislocation (Embick 2007).

The focus of this section is examples likes those in (3) and (4), in which the reduplicant can either be suffixed with -yi- or prefixed with a TAM morpheme pulled in from the left. This asymmetry, between augmentation on the right and circumscription on the left, is an important one, that is discussed in Section 5.1. We will begin with examples including a reduplicated object marker, that are analyzed in Hyman et al. within the Morphosyntactic Doubling framework of Inkelas and Zoll (2005). 


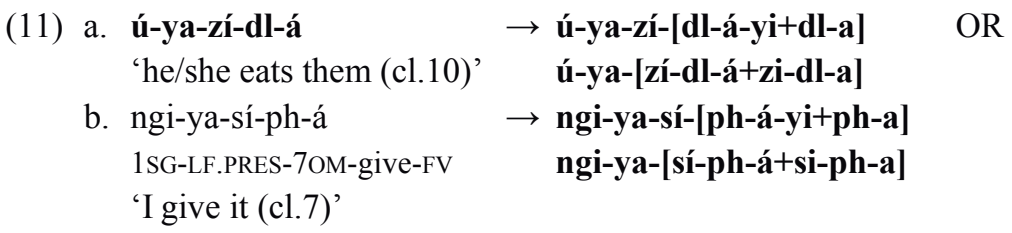

As stated above, in Hyman et al.'s analysis, the options in which the OM is included in RED present an instance of Macrostem doubling. The examples with -yi- augmentation are stemdoubling alone, and the -yi- is present to satisfy the disyllabicity requirement exerted on RED.

Although reduplication of prefixal morphemes seems to be limited to the OM in Ndebele, the new data from Zulu show that several prefixal morphemes can appear in RED, provided they are left-adjacent to the root:

(12) a. u-ya-dl-á 'you eat'

b. bá-ya-mb-a 'they dig'

c. u-sá-dl-á 'you're still eating'

d. bá-sá-lw-a 'they're still fighting' $\rightarrow$

e. ú-zam-a úku-lw-a

'(S)he's trying to fight'

f. lí-qál-a úku-n-á

'it is starting to rain' $\rightarrow$ u-[ya-dl-á+ya-dl-a] u-ya-[dl-á-yi+dl-a]

$\rightarrow$ bá-[ya-mb-a+ya-mb-a] bá-ya-[mb-a-yi+mb-a]

$\rightarrow$ u-[sá-dl-á+sa-dl-a] u-sá-[dl-á-yi+dl-a] bá-[sá-lw-a+sa-lw-a] bá-sá-[lw-a-yi+lw-a]
.... úku-[lw-a-yi+lw-a]

$\rightarrow$ lí-qál-a ú-[ku-ná+ku-na]

.... úku-[n-á-yi+n-a] $\checkmark$ Zulu, *Ndebele

$\checkmark$ Zulu, $\checkmark$ Ndebele

$\checkmark$ Zulu, *Ndebele

$\checkmark$ Zulu, $\checkmark$ Ndebele

$\checkmark$ Zulu, *Ndebele

$\checkmark$ Zulu, $\checkmark$ Ndebele

$\checkmark$ Zulu, *Ndebele

$\checkmark$ Zulu, $\checkmark$ Ndebele

$\checkmark$ Zulu, $*$ Ndebele

$\checkmark$ Zulu, $\checkmark$ Ndebele

$\checkmark$ Zulu, *Ndebele

$\checkmark$ Zulu, $\checkmark$ Ndebele

Unlike $\mathrm{OM}+$ stem $=$ Macrostem, there are no pre-established morphosyntactic constituents that correspond to $\mathbf{y a}+$ stem, sá + stem, or infinitival $\mathbf{k u}+$ stem so a structural doubling account is less convincing for these examples. However, in the analysis proposed here, accounting for -ya-,-sá-, or -ku- in RED is the same as accounting for an OM. This is because reduplication interacts with phonological objects rather than directly with morphosyntactic structure, implying that any morpheme/syllable immediately to the left of the root that participates in reduplication should be equally accessible to reduplication. However, it is not the case that all morphemes preceding the root can be reduplicated; this is discussed in Section 8.1.1.

5.1 The Action of Local Dislocation in reduplication. Following Rackowski (1999), I schematize the morphemes present in the verb complex as X Y Z. When a verb stem $(\mathrm{Z})$ is minimally CVC-a, RED is prefixed to the root and copies material from its right: X Y RED Z. But in cases when $\mathrm{Z}$ is sub-minimal (-dl- 'eat', -zw- 'perceive'), there are two options for RED's alignment within this X Y Z string. It can either stay in its natural, default position, in which case RED's template will be filled out by the empty augmentative morpheme -yi-, or RED can be realized in a different position, and include material that it does not scope over. In this scenario, it can be represented as X RED Y Z, and RED copies material from Y as well as Z. Crucially, for roots that consist solely of a consonantal element (like -dl- , -zw- ), the X element must not be null since the first syllabic constituent in the verb complex, like subject markers cannot reduplicate. 
The process by which the RED template and a prefixal morpheme "switch" positions involves "local dislocation" of the RED template (Embick 2007), and essentially has the effect of prosodic circumscription (Lombardi and McCarthy 1991, McCarthy 2000). Local dislocation only applies to phonological objects, so the morphosyntactic status or affiliation of the morphemes involved is not accessible to the process. Instead, their linear order in the string of the verb complex is largely responsible for whether or not they can reduplicate.

Local dislocation involves the re-ordering of string-adjacent elements that are linearly adjacent to each other. This process necessarily occurs after the hierarchical structure has been linearized; in Embick (2007) it is defined as a "postsyntactic movement under adjacency" (p. 13). It is important to keep in mind that the object being moved here is the bare $[\sigma \sigma]$ reduplicative template. Significantly, any reduplication that contains material outside the scope of reduplication $(u-y a-[z i-d l a+z i-d l a])$ alternates with a form consisting solely of material within its scope $(u-y a-z i-[d l a-y i+d l a])$. This alternation is taken as evidence for an analysis in which reduplication can take place at various points in the derivation, specifically immediately upon the merging of RED and the cycle of phonological spell-out that it triggers, or at a later point, at which certain morphemes outside the scope of RED can appear in the reduplicant.

Crucially, local dislocation feeds reduplication, and can be formalized as a rule that is triggered in a certain phonological environment, with $\mathrm{Y}$ being the prefixal morpheme that is copied to the reduplicant. This environment obtains when the RED template is followed by a single syllable. When its environment is met, local dislocation can apply so that the prefixal morpheme to the left of RED moves to its right, and can then be copied to fully satisfy the disyllabic template. In cases when the verb stem $(\mathrm{Z})$ is monosyllabic, the RED template and the left-adjacent prefixal morpheme can switch positions:

(13) Local Dislocation in Zulu Reduplication:

a. Morphological representation: $\quad$ Y RED Z $\rightarrow$ RED Y Z

With $Z$ being the verb stem, the position of the Red template and $Y$ can switch so that the material that was formerly left-adjacent to the template is now immediately to its right.

b. Phonological representation: $[\sigma]_{\mathrm{Y}}-[\sigma \sigma]_{\mathrm{RED}} \rightarrow[\sigma \sigma]_{\mathrm{RED}}-[\sigma]_{\mathrm{Y}} /{ }_{-}[\sigma]_{\mathrm{Z}}$ $\mathrm{Y}$ and the bare disyllabic RED template switch positions when they are followed by a single syllable. 


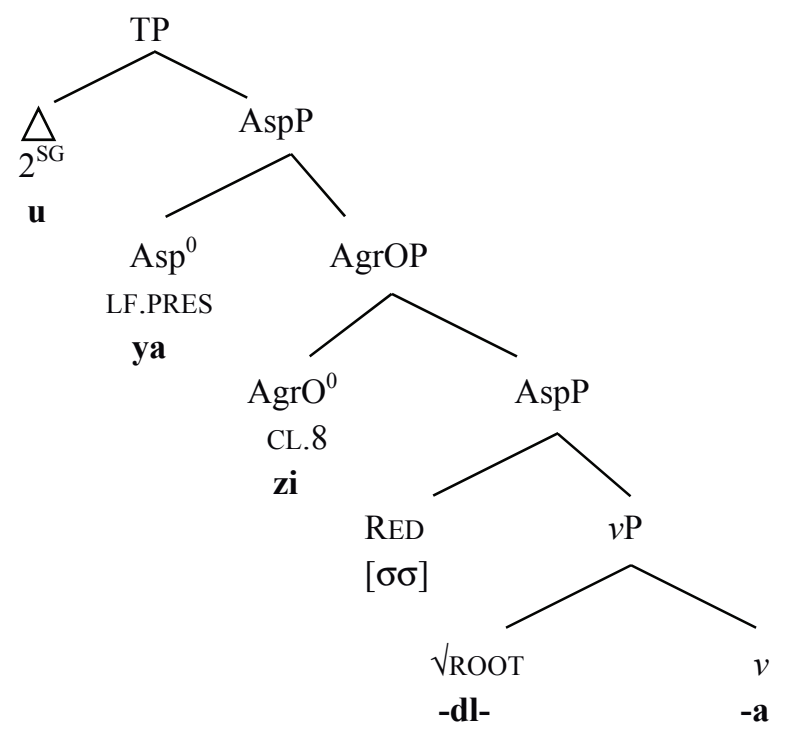

Figure 4. Structure underlying both $u-y a-z i-[d l-a-y i+d l-a]$ and $u-y a-[z i-d l-a+z i-d l-a]$

(14) Deriving u-ya-zi-[dl-a-yi+dl-a] from Fig. 4:

Vocabulary insertion and linearization of $v \mathrm{P}: \quad$-dl-a

VI and linearization triggered by RED: $\quad[\sigma \sigma]-\mathbf{d l}-\mathbf{a}$

Mapping to template: $\quad[\mathbf{d l}-\mathbf{a} \sigma]+\mathbf{d l}-\mathbf{a}$

-yi- rescue to satisfy disyllabicity: $\quad$ [dl-a-yi $]+\mathbf{d l}-\mathbf{a}$

Final cycle (none of the other morphemes

are cyclic/trigger spell-out): $\quad$ u-ya-zi-[dl-a-yi+dl-a]

To derive u-ya-[zí-dl-á+zi-dl-a], the rule of local dislocation applies, with the effect of prosodic circumscription of the prefixal object marker morpheme into the reduplicant.

(15) Deriving u-ya-[zi-dla+zi-dla] from Fig. 4:

Vocabulary insertion and linearization of $v \mathrm{P}: \quad$-dl-a

VI and linearization triggered by RED: $\quad[\sigma \sigma]-\mathbf{d l}-\mathbf{a}$

Final cycle:

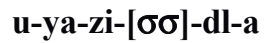

Local dislocation:

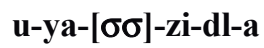

Mapping to template:

u-ya-[zi-dl-a+zi-dl-a]

The mechanism is the same for reduplicants including -ya-, -sá- and -ku- where no object marker is present. Under this analysis, there is no qualitative distinction between the object marker and the other prefixal morphemes that can participate in reduplication. The ability of the $\mathrm{OM}$ to reduplicate is not tied to it belonging to the Macrostem, but rather its linear position as left adjacent to the root, and the RED template. The fact that reduplication of prefixal morphemes is not limited to object markers alone calls into question what Hyman et al. claim to be special about 
the reduplication of OMs- specifically that OMs reduplicate when the Macrostem is targeted as the domain of reduplication. Rather than privileging the morphosyntactic constituent of the Macrostem as the target of reduplication, a more accurate description refers to the phonological entity of the syllable left-adjacent to the root.

Copying proceeds left-to-right, and in order for a constituent to be "available" for reduplication, it must be to the right of the RED template as the template contains the instruction to copy from material to its right. This holds whether the constituent that gets copied consists of the root + default verbal -a alone, or prefixal material too. Put another way, copying works exclusively on material to the right of the template, but in cases of sub-minimal roots, material can be brought in from the left via the action of local dislocation. However, once copying is initiated, the RED template simply copies the first two syllables of the phonological string to its right; if this string is monosyllabic, it is augmented with -yi-.

\section{The inclusion of "inflectional" material in Zulu and Ndebele reduplication}

The Ndebele data discussed here, specifically the inclusion of the object marker in the reduplicant, are analyzed in Hyman et al., but the main question is, what do the new Zulu data add to the picture of Nguni reduplication? Let us return to the examples in (9), in which the judgments from Zulu and Ndebele agree insofar as suffixal inflectional material is barred from appearing in the reduplicant:
a. a-ngi-fúnd-i
'I don't study'
$\rightarrow$ a-ngi-[fúnd-a+fund-i]
NEG-1SG-study-FV.NEG
b. ni-fúnd-e
'You (pl) study (subjunctive)
* a-ngi-[fund-i+fund-i]
2PL-study-FV.SBJ
$\rightarrow$ ni-[fúnd-a+fund-e]
* ni-[fund-e+fund-e]

The Distributed Morphology-copying analysis of why these final vowels are unable to reduplicate is presented in Section 3 (the default final vowel -a is taken to be the phonological realization of the verbalizing head), while Hyman et al. employ the constraint *INFL to explain why the final vowels expressing negation or irrealis are barred from appearing on RED. In their analysis, the reduplicant is constrained to not contain any inflectional material, and this constraint goes unviolated.

However, all the prefixal morphemes that do appear in the reduplicant in Zulu must be classified as inflectional, given any general non-controversial interpretation of the distinction between inflectional and derivational morphology. It is also relevant to point out that the semantics of RED would lead to this morpheme being classified as inflectional itself, since its meaning is essentially aspectual, and it is not category-changing, nor does it manipulate or otherwise affect the verb's argument structure (though as a reviewer points out, classifying RED as straightforwardly inflectional or derivational is not so clearcut). The table below shows that what's meaningful is not labeling a morpheme with an "inflectional" label. Instead, the relevant points are 1) whether it is structurally within the scope of RED, and 2) whether it is prefixed or suffixed to the root. 


\begin{tabular}{|l|l|l|}
\hline & Zulu & Ndebele \\
\hline Non-inflectional material & $\checkmark$ & $\checkmark$ \\
\hline Suffixal inflectional material & $*$ & $*$ \\
\hline Prefixal inflectional material (other than object marker) & $\checkmark$ & $*$ \\
\hline
\end{tabular}

Table 1. Inflectional material and reduplication in Zulu and Ndebele

The Zulu examples showing reduplication of prefixal morphemes demonstrate that labeling a morpheme as inflectional is not sufficient to explain the data. What matters is not whether a morpheme is inflectional, but to what side of the root it occurs.

\section{The left-right asymmetry in reduplication of "inflectional" morphemes}

As described in Section 5.1, local dislocation plays an important role in accounting for the leftright asymmetry in reduplication, also known as a "conscription asymmetry." The X Y RED Z representation also explains why only material to the left of the root is allowed to reduplicate. We will see a noteworthy asymmetry between the long form prefixal marker -ya-, and the suffixal long form recent past marker -il-. Both are markers of a verb being final in a syntactic domain, but we have seen that the former can reduplicate, and the latter cannot (18), *u-[dl-il-a+dl-il-e]. The approach implemented here takes the RED morpheme to be linearized as a bare $[\sigma \sigma]$ template in the phonological string of the verb. This $[\sigma \sigma]$ template comes with an instruction to copy from material to its right, so it follows that flipping its position with the root would be unattested.

If the root is the very constituent targeted by RED, and if the RED template is moved to the right, it would also be to the right of the stem. The order RED-stem would be flipped to the order stem-RED, and stem material would fail to be copied into the RED template. The difference in behavior between prefixal -ya- and suffixal -il- also highlights why reduplication is better classified as "phonological" than "morphosyntactic"; although morphosyntactic structure is implicated in the operation, the copying at the heart of reduplication is a phonological process.

When the verb is phrase-final, a long form (also termed disjunctive) marker is required (Buell 2006, van der Spuy 1993). This morpheme is -ya- in the present and -il- in the recent past. In (17) long forms are on the left and short forms, followed by a low-attached/phrase-internal adverb, are on the right.

Long Form

a. u-ya-dl-á

b. u-ya-fúnd-a

c. u-dl-il-e

d. u-fúnd-il-e
'You are eating.' vs.

'You are reading.' vs.

'You ate.'

'You read.'

\section{Short Form}

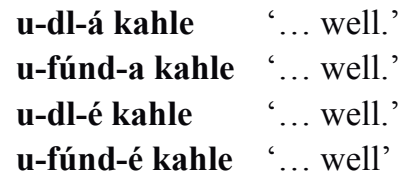

The morphemes serve the same function, and it would be reasonable (if not required) to assume they originate in similar syntactic positions and be equally accessible to RED. However, while -yacan reduplicate, -il- cannot:

$$
\begin{aligned}
(18) \text { a. } \quad \text { u-ya-dla } \rightarrow & \text { u-ya-[dla-yi+dla] } \\
& \text { u-[ya-dla+ya-dla] }
\end{aligned}
$$

b. u-dl-il-e $\rightarrow$ u-[dla-yi+dl-il-e]

* u-[dlil-a+dl-il-e] 
In light of the derivation in (15), the contrast between prefixal -ya- and suffixal -il- falls out naturally.

(19) Deriving the left-right asymmetry in reduplication

\begin{tabular}{|c|c|c|}
\hline & {$[[[[[d l] v]$ RED $]$ LF.PRES $] 2 \mathrm{SG}]$} & {$[[[[[[d l] v] \mathrm{RED}]$ LF.PRES $]$ 2SG] } \\
\hline VI and linearization: & $-\mathrm{dl}-\mathrm{a}$ & $-\mathrm{dl}-\mathrm{a}$ \\
\hline VI and lin. from RED: & {$[\sigma \sigma]-d l-a$} & {$[\sigma \sigma]-d l-a$} \\
\hline VI of LF.PRES and 2SG: & 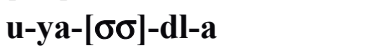 & 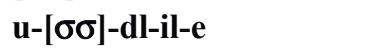 \\
\hline Local dislocation: & 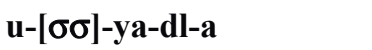 & 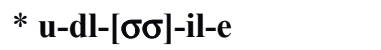 \\
\hline Map to template: & u-[ya-dla+ya-dla] & crashes \\
\hline
\end{tabular}

With prefixal material, local dislocation provides another means of reduplicating monosyllabic stems in addition to augmentation with -yi-, however it is blocked from applying productively to suffixal morphemes because doing so misaligns the template and the root. Furthermore, the rule of local dislocation is formulated to apply only if there is a single syllable to the right of template. The upshot is that the monosyllabicity requirement along with the reduplicant being a prefix to the stem in Zulu make it so that local dislocation is constrained to apply only with prefixal morphemes.

The role of linearity in reduplication emphasizes its position solidly in the phonological component of the grammar; although it is affected by morphosyntactic structure, copying operates on a structure that has been linearized. That is to say, reduplication as a template-filling operation is a process that interacts exclusively with a phonological string.

\section{Stems with a prosodic shape of VCV}

We have seen that with CV stems, there is a set of prefixal morphemes that is permitted to participate in reduplication. We turn now to VCV stems, a prosodic class including forms like -enza 'do, make', -akha 'build', -eba 'steal', and -ába 'share'. Stems of this shape take all the morphemes that reduplicate with consonantal roots, along with subject markers, which are not allowed to reduplicate before $\mathrm{CV}$ roots:

(20) a. u-lwa 'you fight'

b. ni-má 'you (pl) get up'

c. si-akh-a $\rightarrow$ s-akh-a 'we build'

d. u-enz-a $\rightarrow$ w-enza-a 'you make'

$$
\begin{aligned}
\rightarrow & \text { u-[lwa-yi+lwa] } \\
* & {[\mathbf{u}-\text { lwa-(w)u-lwa] }} \\
\rightarrow & \text { ni-[má-yi+ma] } \\
* & {[\text { ni-ma+ni-ma] }} \\
\rightarrow & \text { i. }[\text { s-akh-a+s-akh-a] } \\
& \text { ii. s-[akh-a+y-akh-a] } \\
\rightarrow & \text { i. }[\mathbf{w}-\text { enz-a+w-enz-a] } \\
& \text { ii. w-[enza-a+y-enz-a] }
\end{aligned}
$$

At first glance, the process by which the subject markers are included in the reduplicant looks to be a by-product of syllabification, but a closer look reveals that it is in fact sensitive to morphosyntactic structure in interesting and unexpected ways. 
These data immediately call to mind Odden and Odden's well-known work on Kihehe (1985), in which reduplicants include prefixal material only in cases where this material is syllabified together with the stem. For Zulu, the data from subject markers alone support an analysis in line with Aronoff (1988) and Marantz (1987). For both, the syllabification is analyzed as incidental, in that reduplication does not distinguish between the root as the morphosyntactic object it targets and the phonological object of the root, which is syllabified with prefixal material. Put differently, the examples in (20c, d) support a view of reduplication as a phonological process that interacts with phonological units, i.e., the syllable. Despite morphosyntactically targeting the root, the phonological unit of the root looks to be inseparable from the subject marker with which it has syllabified.

Marantz analyzes Odden and Odden's (1985) Kihehe data that are very similar to (20c, d) (Marantz (1987) ex. (1), Odden (1993) ex. (39)). The infinitival prefix ku- is normally excluded from reduplicating, but before a vowel-initial root it is included in the reduplicant:
a. ku-teleka
'to cook'
$\rightarrow$ ku-teleka-teleka
'to cook a bit'
b. kw-iita (/ku-ita/)
'to spill'
$\rightarrow$ kw-iita-kw-iita
'to spill a bit'

Marantz writes that the inclusion of the infinitive prefix with the reduplicant is due to the strictly phonological process of syllabification:

What is being targeted for copying in Kihehe full morpheme reduplication is the set of syllables that contain all the phonological material corresponding to a verb root. These syllables might also contain material associated with other morphemes, but the copying of reduplication doesn't care about that. (Marantz 1987: 205)

For Zulu subject markers, Marantz's assertion appears to accurately describe the facts, but the analysis underlying them is far from straightforward. How do we describe reduplication in a way that lets us rule out the inclusion of moraic subject markers, but allow for those that are glided/non-moraic? Assuming the structure in Figure 5:

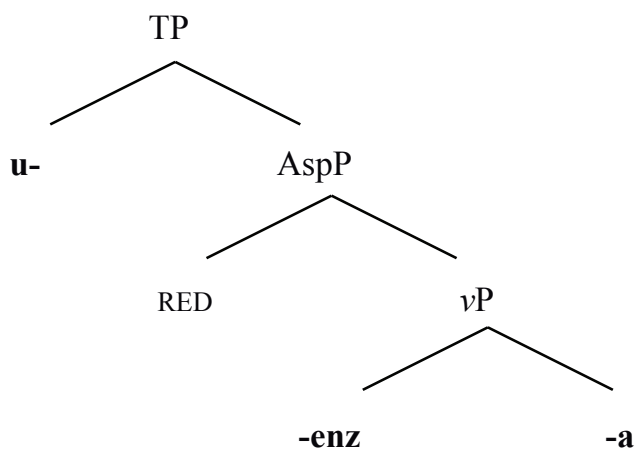

Figure 5. Structure for $w-[e n z-a+y-e n z-a]$ and $[w-e n z-a+w-e n z-a]$

If RED targets the $v \mathrm{P}$, we will see the $\mathbf{w}-[\mathbf{e n z}-\mathbf{a}+\mathbf{y}-\mathbf{e n z}-\mathbf{a}]$ reduplication, since $-\mathbf{y}$ - is "emergency hiatus repair" on analogy with -yi- as a rescue morpheme. In order to explain the presence of the 
non-moraic subject marker, it is potentially helpful to assume that the $[\sigma \sigma]$ is not CVCV, and that the reduplication does not crash if the initial syllable lacks an onset. ${ }^{7}$

However, with an intermediate representation of: -enz-a+_enz-a, it's difficult to see how to interpolate the subject marker onto the base (the righthand constituent) without a backcopying analysis (McCarthy and Prince 1995). Regardless of how to best account for the reduplication of subject markers with VCV stems, data from negation show that phonological syllabification alone is not sufficient to explain the facts, and that in this case, reference to underlying structure is necessary as well.

8.1 VCV stems and negation. In the present, negation surfaces as an initial a- and final -i and also conditions the realization of the 3SG subject marker as ká-:

a-ká-hámb-i 'he doesn't walk' $\rightarrow$

a-ká-[hámb-a+hamb-i]

* a-ka-[hamb-i+hamb-i]

Negation scopes over reduplication in all cases, so that the meaning of the reduplication in (22) is "he doesn't do a bad job of walking" rather than "he does a bad job of not walking”. When a VCV stem is inflected for negation, the negation is reflected in the subject marker, which reduplicates, but the final -i, does not (along with the initial a- which in any case is outside the prosodic domain of reduplication):

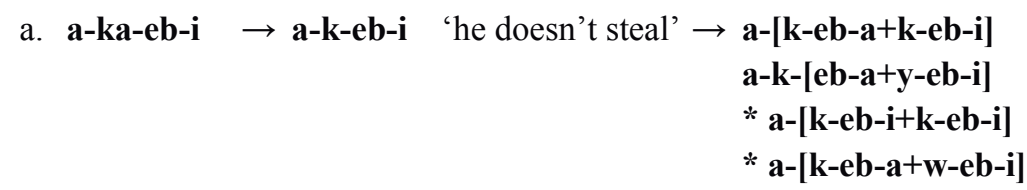

b. a-ka-os-i $\rightarrow$ a-k-os-i 'he doesn't roast' $\rightarrow$ a-[k-os-a+k-os-i]

$*$ a-[k-os-i+k-os-i]

$\checkmark$ a-[k-os-a+w-os-i]

The form with $w$ on the base is grammatical in the last example in (23b), but it is crucial to note that the $[\mathrm{w}]$ is not a reflex of the subject marker; instead it is the epenthetic glide [y] assimilating to the backness of the following [o] (Doke 1927: 1992).

8.1.1 Negation behaves differently. If the inclusion of the subject marker before VC roots (whether the unmarked $\mathbf{w}$ - or the $\mathbf{k}(\mathbf{a})$ - that appears under negation) is simply an effect of syllabification unrelated to underlying structure, we would expect any morpheme occurring in this position to be included in RED without issue. However, this is not what we find, and there is an interesting range of interaction between underlying structure and phonological realization.

We saw that in the present, negation surfaces as an initial a- and final -i, but it is not possible to assign the present tense to one of these morphemes and negation to the other. These morphemes are often related to negation in other tense aspect paradigms, in the recent past:

7 Zulu allows vowel-initial syllables word-initially, it is strictly CV word-internally as an epiphenomenon of a ban on hiatus (Doke 1926). 


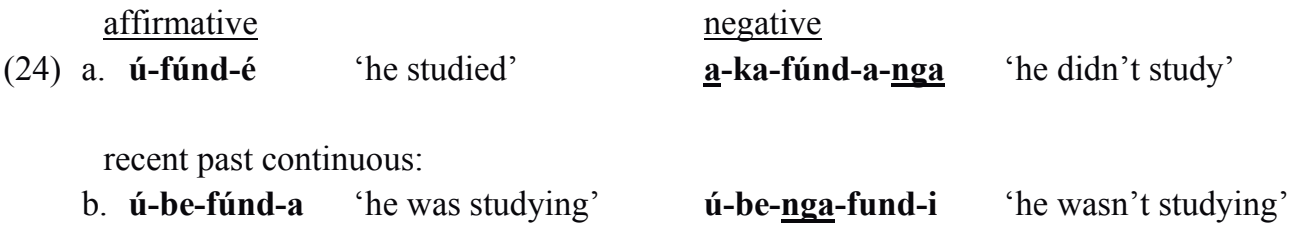

But, it is the -nga- morpheme, along with other markers that vary according to the TAM paradigm, that is found in the majority of negative forms in the language and can occur in a variety of positions (Güldemann 1999). As shown in (24a,b), it can be suffixed or prefixed to the root; additionally in the remote past perfect, it can occur in both positions:

$\begin{array}{ll}\text { wá-(y)e-fúnd-a } & \text { 'he studied (a long time ago)' } \\ \text { wa-(y)e-nga-funda-nga } & \text { 'he didn't study (a long time ago)' }\end{array}$

Since -fúnda is fully disyllabic, we wouldn't expect any of the negative forms in (24) or (25) to include -nga- in the reduplicant. Given the syllabification conventions we've already seen for Zulu, in the case of a VC root, the hypothesis would have to be that an occurrence of -ngaimmediately preceding the root should be allowed to reduplicate since it is immediately leftadjacent to the root. However, including -nga- in RED is not acceptable; for the negative of the recent past continuous (the same tense as the lefthand example in (24b)):
(26) a. ú-be-nga-eb-i $\rightarrow$ ú-be-ng-eb-i $\rightarrow \quad *$ u-be-[ng-eb-a+ng-eb-i]
'He wasn't stealing' $\quad *$ u-be-[ng-eb-i+ng-eb-i]
$\checkmark$ ú-be-ng-[eb-a+(y)-ebi]
b. ú-be-nga-os-i $\rightarrow$ ú-be-ng-os-i $\rightarrow$ *u-be-[ng-os-a+ng-os-i]
'He wasn't roasting' $\quad *$ u-be-[ng-os-i+ng-os-i]
$\checkmark$ ú-be-ng-[os-a+(w)-osi]

To show that a structural explanation of the examples in (26) is indeed necessary, the prenasalized velar is permitted in the reduplicant if it is from the 1SG subject marker ngi- $(a, b)$, or the 1sg object marker -ngí- (c):
a. ngi-eb-a 'I steal' $\rightarrow \quad$ [ng-eb-a+ng-eb-a] and in the present negative:
b. a-ng-eb-i 'I don't steal' $\rightarrow$ a-[ng-eb-a+ng-eb-i]
c. u-ng(í)-ang-a 'You hug me' $\rightarrow$ u-[ng-ang-a+ng-ang-a]

Along with the data from consonantal roots, the examples showing the interaction between negation and VCV stems demonstrate that both structure and surface form must be taken into consideration to account for the data on which morphemes may be included in the reduplicant in Zulu. 


\section{Tone}

In this section, we will look at how tone interacts with reduplication. Although this article focuses principally on sub-minimal stems, in order to understand how tone rules function when they are not constrained or inhibited by stem length, it is helpful to look first at longer, non-reduplicated stems: those that are minimally four syllables, since this is the minimum length within which all the tone rules can apply free of length restrictions (Khumalo 1981, 1982; Downing 1990, 2001b; Cassimjee and Kisseberth 2001).

The key finding presented in this section is that a morpheme's affiliation with the prefixal domain is voided if this morpheme is reduplicated; this is shown with the durative prefixal morpheme -sá-. These data, taken together with tonal data from reduplicated di- and trisyllabic stems, favor an analysis in which reduplication does not consist of two occurrences of the verb stem as in Inkelas \& Zoll's Morphological Doubling Theory, but rather of a copying operation that copies/targets the harmonic autosegmental tier as well as the melodic segmental tier of phonological representation. Finally, I show that grammatical tone is assigned subsequent to reduplication, and treats the verb complex as a single constituent, rather than targeting the reduplicant and base individually.

9.1 Overview of Zulu tone ${ }^{8}$. Zulu is a two-toned system, high and toneless/low; following the literature, we will assume that $\mathrm{H}$ tones are marked underlyingly, and low is the default for syllables that are not specified H (Pulleyblank 1986; Maddieson 1978). While each syllable of a noun can be tonally specified (Rycroft 1963; Laughren 1984), verb roots are only high or toneless, regardless of how many syllables they contain. The extension suffixes present in the examples below: causative -is-, applicative -el-, reciprocal -an-, are all toneless and simply extend the tonal domain of the root.

The examples we will be looking at in this section are all phrase-final, meaning they are subject to a rule of penultimate lengthening (van der Spuy 1993; Hyman 2009). Provided a phrasefinal verb complex is prosodically "big enough"-specifically, a stem of minimally four syllables - a high tone $(\mathrm{H})$ will surface on the antepenult, regardless of where it is sponsored or underlyingly linked (Downing 1990; Cope 1959). ${ }^{9}$ The penultimate syllable lengthens and the $\mathrm{H}$ shifts to the antepenult. Following convention, in the examples below the underlying location of the high tone is underlined, and its surface position is marked with an acute accent. For high-toned roots, the $\mathrm{H}$ is marked as linked to the first mora of the root. Penultimate lengthening is marked in the first several examples but not elsewhere, since it applies across the board in all the examples cited here as all forms given are phrase-final.

9.2 Tone in non-reduplicated and reduplicated verbs. The examples in (29) and (30) show the patterns of tone realization for four syllable (a-b), trisyllabic (c-d), disyllabic (e-f), and monosyllabic (g-h) stems. For descriptive purposes, it is helpful to lay out an a-theoretical "scale" to explain the position in which a high tone surfaces.

8 The tonal system discussed here is characteristic of the Zululand dialect, rather than the Natal/Durban dialect. See Cassimjee and Kisseberth, Downing (2001b), and Khumalo (1981, 1982) for the tonal differences between the dialects.

9 Consequently, if the TBU is the final, penultimate, or antepenultimate syllable, some of these patterns will be obscured. 
(28) Understanding where a high tone surfaces for Zululand Zulu (Downing 2001b; Cassimjee and Kisseberth 2001):

a) if $\mathrm{H}$ is linked to a TBU to the left of the antepenult, $\mathrm{H}$ surfaces on antepenult

b) if $\mathrm{H}$ is linked to antepenult, $\mathrm{H}$ surfaces on penult

c) if $\mathrm{H}$ is linked to penult, $\mathrm{H}$ surfaces on penult (in position where it is sponsored)

d) if $\mathrm{H}$ is linked to final syllable, $\mathrm{H}$ surfaces on final syllable (in position where it is sponsored)

When there is a single $\mathrm{H}$ in the verb complex, it surfaces on the antepenult (29), provided the antepenult is not where it is underlyingly linked (30):

(29) a. u-ya-shümáye:la 'you are preaching' 2SG-LF-preach

b. ba-ya-beléth-i:sa 'they are helping to carry' 3PL-LF-carry-CAUS

c. si-sa-beléth-i:sa 'we are still helping to carry'

1PL-DUR-carry-CAUS

d. ba-ya-béle:tha 'they are carrying'

3PL-LF-carry

(30) a. i-yá:-hlwa

'it is getting dark'

SM.9-LF-dark

b. si-ya-sebé:nza 'we are working'

1PL-LF-work

For disyllabic and monosyllabic stems with an underlying $\mathrm{H}$, it will always surface in the position where it is underlyingly linked:
a. ni-ya-hlé:ba
$2^{\mathrm{PL}}$-LF-whisper
'you (pl) are whispering'
b. u-ya:-má
$2^{\mathrm{SG}}$-LF-stand
'you are getting up'

A reduplicated verb has been shown to behave like a single tonal domain, but identifying the underlying position of a stem-internal $\mathrm{H}$ is challenging. For $(32 \mathrm{a}, \mathrm{b})$ the pattern of tone realization is amenable to an analysis in which it is underlyingly linked to the initial syllable of the base, but for $(32 \mathrm{c}, \mathrm{d})$, the RED+base complex is behaving as a non-reduplicated stem, with the H linked to the first syllable of RED (similar data reported for mutually intelligible Swati in Downing (2003)). In (32), the constituent that is underlined is where it looks like the tone is linked, but sometimes this is in RED and sometimes in the base: 
(32) a. si-ya-bonísa:na

b. si-ya-lalé:la

c. si-ya-mé:ma

d. si-ya:-fá 'we show e.o.'

'we listen'

'we yell'

'we die' $\rightarrow$ si-ya-[boni+bonísa:na]

$\rightarrow$ si-ya-[lale+lalé:la]

* si-ya-[lale+lále:la]

$\rightarrow$ si-ya-[memá+me:ma]

$\rightarrow$ si-ya-[fa-yí:+fa]

How do the data from reduplications compare with the behavior of two high tones with a single domain (such as the Macrostem) for non-reduplicated forms? When this situation obtains, the lefthand $\mathrm{H}$ deletes (Goldsmith 1984), and the Macrostem constituent, consisting of the object marker and the stem, displays tonal behavior similar to the RED+base complex:

(33) Meeussen's Rule in Zulu deletes OM H and preserves stem H (Downing 1990)
a. u-ya-yị-bonís-el-a
'you are showing for it (cl 9)'
b. ngi-ya-si-fümána
'I am catching up to it (cl 7)'
c. ni-ya-wạ-khéla
'you are picking for them ( $\mathrm{cl} 4)$ '
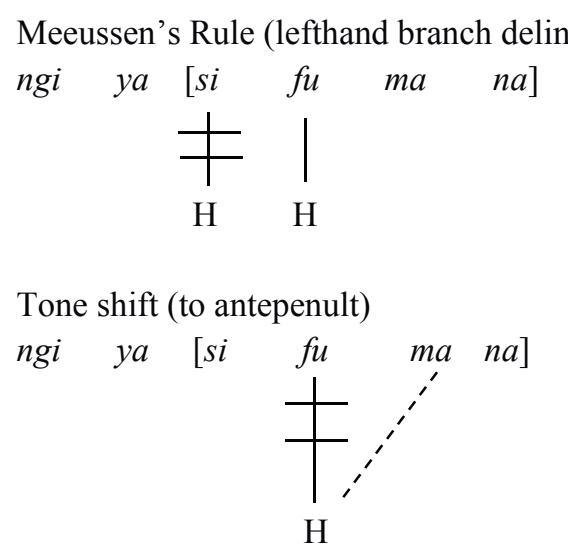

Figure 7. Action of Meeussen's Rule in Macrostem (bracketed)

Although it is somewhat difficult to account for the forms in $(32 \mathrm{c}, \mathrm{d})$, if we assume that both RED and the base enter with high tones, we can predict where the tone will ultimately surface with the following constraints (Hyman, p.c.):

(34) The realization of tone in reduplications of high-toned stems

a. $\mathrm{H}$ to antepenult

b. H cannot be realized on its sponsor/where it is underlyingly linked (assuming the initial syllable of both RED and the base bear a high tone)

c. $\left.{ }^{*} \mathrm{H}\right]_{\mathrm{W}}$ (no high on final syllable)

d. RED+base forms a single tonal domain = can only contain a single output $\mathrm{H}$

9.3 The significance of the tonal behavior of $-\mathbf{s a ́}$-. If there are two high tones in separate domains in a verb complex, one linked to a prefixal morpheme and the other to the stem, each will 
surface in its respective domain (if $2 \mathrm{H}$ 's underlyingly linked to different morphemes are realized on adjacent syllables, the second is often downstepped, as shown in $(35 \mathrm{c}, \mathrm{d}))$ :
a. bạ-yá-shumáye:la
'they are preaching'
OR bá-ya-shümáye:la
b. si-sá-sebé:nza
c. bá-'-phúza
'we are still working'
d. si-sá:- '-
'we drink'
'we are still dying'

(36)
a. bá-'-phúza
$\rightarrow \quad$ bá--[phuzá+phuza]
b. 任- 'thánda
$\rightarrow \quad$ ú-[thandátthanda]
c. ni-sáa - thánda
$\rightarrow$
ni-sá-[thandá+thanda]

(37) Meeussen's Rule applies in macrostem domain independently of reduplication of object marker

báa-ya-sí-phá $\quad$ 'they give it (cl.7) $\rightarrow$ a. bá-ya-[si-pha+sí-pha]

b. bá-ya-si--[pha-yít+pha]

What (37b) shows is that even when the object marker does not appear in the reduplicant, the Macrostem is still an intact constituent because it contains only a single high tone on the surface. Despite there being two H's that are underlyingly linked (to the OM -sí-, and the stem phá), the Macrostem, here consisting of the OM and the RED+base complex, behaves as a single domain for high tone realization.

The non-reduplicated forms in (38) below demonstrate that -sá- is in the prefixal domain and outside the Macrostem because, unlike object markers, it does not undergo Meeussen's Rule when it is adjacent to a high-toned stem, i.e. it retains its high tone when it precedes a high-toned verb. However, when it appears in the reduplicant with a high-toned stem, -sá- undergoes Meeussen's Rule and loses its high tone.

(38) a. si-sá-sebénza

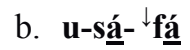

$$
\begin{aligned}
& \text { 'we are still working' } \rightarrow \text { si-sá-[sebe+sebénza] } \\
& \text { 'you are still dying' } \rightarrow \text { u-[sa } \underline{\mathbf{a}}-\mathbf{f} \underline{\mathbf{f}}+\mathbf{s a ́}-\mathbf{f a}]
\end{aligned}
$$

Example (38b) shows that one of the two underlying H's in the non-reduplicated form is deleted when -sá- is reduplicated. The pattern shown with -sá- is identical to the tone of the toneless morpheme -ya- when it is reduplicated.

(39) a. u-ya-fá

$$
\text { 'you're dying' }
$$$$
\rightarrow \text { u-[ya-fa }+ \text { +yá-fa] }
$$

The tonal patterns of reduplications of a high-toned monosyllabic stem are identical whether the prefixal morpheme appearing in the reduplication is high-toned -sá- or toneless -ya-, presenting strong evidence that when prefixal morphemes are reduplicated, they lose their prefixal affiliation and undergo the tonal alternations characteristic of (Macro)stem-internal morphemes, specifically object markers. For the sake of comparison, below is the reduplication of -sá- with a low-toned 
root. In this case, the tone of -sá- is indisputably preserved, as it is the only high-toned morpheme present in the construction.

$$
\text { u-sá-lw-a } \quad \text { 'you're still fighting' } \rightarrow \text { u-[sa-lwá+sa-lwa] }
$$

9.4 The interaction of reduplication and grammatical tone. The data from reduplications of disyllabic and trisyllabic stems (32) show the complications involved with asserting whether hightones are linked to the reduplicant, the base, or both constituents, consequently making it difficult to fully understand the ordering of the processes of tone assignment, spreading, and reduplication. However, when we look at grammatical tones, those that are linked with certain paradigms, we can see that reduplication certainly happens before these tones associate with the verb complex. Up to this point, the tones that have been discussed are lexical tones, meaning tones that are linked to specific morphemes, like subject markers or verb roots. Grammatical tones behave somewhat differently, as they "dock" at an edge of the verb complex and often target multiple syllables, or interact with a "window" containing a certain number of syllables at one edge or the other (Claughton 1983).

For instance, the negative present is characterized as an initial a- and final -i, but it is also characterized by a high tone that targets the penult (Buell 2005, p. 83):

$$
\text { ngi-ya-namathelis-a 'I stick' }
$$$$
\rightarrow \text { a-ngi-namathelís-i }
$$

'I don't stick'

Under reduplication, the final vowel of negation $-\boldsymbol{i}$ cannot occur in the reduplicant, nor can the penultimate high the suffix (or mood) contributes:
a. ngi-ya-khaph-a 'I lead'
b. a-ngi-kháph-i

The ungrammatical examples in (42) show that neither the segmental nor tonal realization correlated with negation may appear on the reduplicant, and present strong evidence in favor of an analysis in which reduplication takes place prior to the spell-out or phonological processing of other TAM/inflectional morphemes. ${ }^{10}$

This is the case even for paradigms bearing a suffix with the default segmental content of the final vowel, $\mathbf{- a}$, as we find with the negative past subjunctive. This TAM paradigm is marked by an -a- that comes after the subject marker, and this morpheme is in turn followed by -nga-. Tonally, there is an $\mathrm{HH}$ pattern that docks over the last two syllables of the verb complex (the tense carries a consecutive reading):

10 A reviewer astutely points out that it's impossible to tell whether this surface pattern is the result of a single underlying tone, or follows from the action of Meeussen's Rule which would have deleted the tone off the reduplicant. 
(43) ng-a-nga-kháph-á 'and then I didn’t lead' $\rightarrow$ nga-nga-[khaph-a+kháph-á]

1SG-PST-NEG-lead-FV.SBJ

* nga-nga-[kháph-á+kháph-á]

Even when there is no distinct segmental suffix that characterizes a particular paradigm, the tonal suffix cannot target the reduplicant, and must instead dock at the right edge of the full RED+base complex.

The examples in this section support an analysis of the reduplicated verb complex as an object that is derived prior to the tonal effects of TAM morphemes that are structurally outside the scope of the morpheme responsible for reduplication.

\section{Applicability to the other Nguni languages}

Zulu belongs to the Nguni group of Bantu languages, consisting of three other languages with which it is mutually intelligible: Ndebele (Zimbabwe), Swati (Swaziland), and Xhosa (Western South Africa). As documented in Sibanda (2004) and Hyman et al. (2009), reduplication of prefixal material in Ndebele is limited to the object marker alone. Since Ndebele does not allow reduplication of -ya- or any prefixal morphemes with the exception of the object marker, it is difficult to see how the approach relying on local dislocation would account for this pattern.

One possibility that requires further investigation is that the grammar of reduplication is not stable in the Nguni languages, and that it may be in the process of changing from drawing solely on stem-internal material to being able to include prefixal material as well, which is the current picture we see for Zulu. A point in support of this claim is that in earlier work mentioning Zulu reduplication (Doke 1927), the only grammatical reduplications for sub-minimal roots are those containing -yi-, and it was much more recent fieldwork undertaken in 2011-2015 that revealed the new judgments presented here.

In Swati (Kiyomi and Davis 1992) and Xhosa (Cassimjee 1998), no syllabic prefixal morphemes are reported as being able to reduplicate. The action of local dislocation in reduplication seems to best describe the phenomena observed in Zulu. However, in other closely related languages, the nucleus of the first syllable of the template must be filled with material from the verb stem, and not prefixal material. ${ }^{11}$

\section{Conclusion}

This paper has presented data from Zulu that show the repertoire of morphemes available for reduplication extends one syllable leftward into the prefixal domain beyond the object marker alone. These data lend themselves to an analysis in which reduplication is best understood as a copying operation that interacts with phonological constituents, rather than a morphosyntactic operation that interacts with hierarchical constituents. However, examples from negation show that simply being left-adjacent to the root does not automatically mean that a morpheme is allowed to reduplicate. Tonal data illustrate the effect of reduplication on the distinction between prefix and stem tonal domains, and make the case that a morpheme's prefixal affiliation is voided if it is included in the reduplicant. There remain a number of outstanding issues involving the interplay

11 Both Swati and Xhosa can reduplicate prefixal morphemes before VC roots, including the subject marker (Downing 1998, 2009). These facts are the same as the Zulu data presented in Section 8. 
of phonological and morphosyntactic objects, as the Zulu data seem to disregard certain traditional morphosyntactic boundaries while respecting others.

\section{Abbreviations}

$\begin{array}{llll}\text { AUG } & \text { augment } & \text { PERF } & \text { perfective } \\ \text { DUR } & \text { durative } & \text { PL } & \text { plural } \\ \text { FV } & \text { final vowel } & \text { PRES } & \text { present } \\ \text { INF } & \text { infinitive } & \text { PST } & \text { ast } \\ \text { LF } & \text { long form verb } & \text { RED } & \text { reduplicant } \\ \text { NEG } & \text { negative } & \text { SBJ } & \text { subjunctive } \\ \text { OM } & \text { object marker } & \text { SG } & \text { singular }\end{array}$

\section{References}

Aronoff, Mark. 1988. Head operations and strata in reduplication: a linear treatment. Yearbook of Morphology 1. 1-15.

Bobaljik, Jonathan. 2000. The ins and outs of contextual allomorphy. University of Maryland Working Papers in Linguistics 10. 35-71.

Buell, Leston. 2005. Issues in Zulu verbal morphosyntax. Los Angeles, CA: UCLA Ph.D. dissertation.

Buell, Leston. 2006. The Zulu conjoint/disjoint verb alternation: focus or constituency. ZAS Papers in Linguistics 43. 9-30.

Cassimjee, Farida. 1998. Isixhosa tonology: An Optimal Domains theory analysis. Munich: Lincom Europa.

Cassimjee, Farida and Charles Kisseberth. 2001. Zulu tonology and its relationship to other Nguni languages. In Shigeki Kaji (ed.), Proceedings of the Symposium, Cross-Linguistic Studies of Tonal Phenomena. Tonogenesis, Japanese Accentology, and Other Topics, 327-359. Tokyo: ILCAA.

Claughton, John. 1983. The tones of Xhosa inflections. Grahamstown: Department of African Languages, Rhodes University.

Cook, Toni. 2013. Morphological and phonological structure in Zulu reduplication. Philadelphia, PA: University of Pennsylvania Ph.D. dissertation.

Cope, Anthony. 1959. Zulu tonology. Afrika und Übersee 43. 1-42.

Doke, Clement M. 1926. Phonetics of the Zulu language. Johannesburg: University of the Witwatersrand Press.

Doke, C.M. 1927 [1992]. Textbook of Zulu grammar, $6^{\text {th }}$ edn. London: Longman.

Downing, Laura. 1990. Local and metrical tone shift in Nguni. Studies in African Linguistics 21. 261-317.

Downing, Laura. 1997. Correspondence effects in Siswati reduplication. Studies in the Linguistic Sciences 25. 81-95.

Downing, Laura. 1998. On the prosodic misalignment of onsetless syllables. Natural Language and Linguistic Theory 16. 1-52. 
Downing, Laura. 1999. Verbal reduplication in three Bantu languages. In René Kager, Harry van der Hulst, \& Wim Zonneveld (eds.), The Prosody Morphology Interface, 62-89. Cambridge University Press.

Downing, Laura. 2000. Morphological and prosodic constraints on Kinande verbal reduplication. Phonology 17. 1-38.

Downing, Laura. 2001a. Ungeneralizable minimality in Ndebele. Studies in African Linguistics. 30. 33-58.

Downing, Laura. 2001b. How ambiguity of analysis motivates stem tone change in Durban Zulu. University of Britsih Columbia Working Papers in Linguistics 4. 39-55.

Downing, Laura. 2003. Compounding and tonal non-transfer in Bantu languages. Phonology 20. $1-42$.

Downing, Laura. 2009. Linear disorder in Bantu reduplication. Paper presented at the Workshop on the Division of Labor between Morphology and Phonology \& Fourth Network Meeting, Meertens Instituut, 16-17 January.

Embick, David. 2007. Linearization and local dislocation. Linguistic Analysis 33. 2-35.

Embick, David. 2010. Localism versus globalism in morphology and phonology. Cambridge: MIT Press.

Embick, David. 2015. The morpheme: A theoretical introduction. Berlin: DeGruyter.

Goldsmith, John. 1984. Meeussen's rule. In Mark Aronoff \& Richard Oerhle (eds.), Language sound structure: Studies in phonology, 245-259. Cambridge: MIT Press.

Güldemann, Tom. 1999. The genesis of verbal negation in Bantu and its dependency on functional features of clause types. In Larry Hyman \& Jean-Marie Hombert (eds.), Bantu historical linguistics: Theoretical and empirical perspectives, 545-587. Stanford, CA: CSLI.

Halle, Morris and Alec Marantz. 1993. Distributed Morphology and the pieces of inflection. In Kenneth Hale, Samuel J. Keyser, \& Sylvain Bromberger (eds.), The view from Building 20: Essays in linguistics in honor of Sylvain Bromberger, 111-176. Cambridge: MIT Press.

Harley, Heidi and Rolf Noyer. 1999. Distributed Morphology. Glot International 4. 3-9.

Hyman, Larry. 2007. Reconstructing the Proto-Bantu verbal unit: Internal evidence. Bantu in Bloomsbury: Special issue on Bantu linguistics. SOAS Working Papers in Linguistics 15. 201211.

Hyman, Larry. 2009. Penultimate lengthening in Bantu: Analysis and spread. In Balthasar Bickel, Lenore Grenoble, David Peterson, \& Alan Timberlake (eds.), What's where, why? Language typology and historical contingency: a Fetschrift to honor Johanna Nichols (to appear). Amsterdam: Benjamins.

Hyman, Larry, Sharon Inkelas, and Galen Sibanda. 2009. Morphosyntactic correspondence in Bantu reduplication. In Kristin Hanson \& Sharon Inkelas (eds.), The nature of the word: Essays in honor of Paul Kiparsky, 273-310. Amsterdam: John Benjamins.

Hyman, Larry and Al Mtenje. 1999. Prosodic Morphology and Tone: The case of Chichewa. In René Kager, Harry van der Hulst, \& Wim Zonneveld (eds.), The prosody-morphology interface, 90-133. Cambridge University Press

Inkelas, Sharon and Cheryl Zoll. 2005. Reduplication: Doubling in Morphology. Cambridge University Press.

Khumalo, James S. 1981. Zulu tonology, part 1. African Studies 40. 53-130.

Khumalo, James S. 1982. Zulu tonology, part 2. African Studies 41. 3-126. 
Kisseberth, Charles. 1984. Digo Tonology. In George Clements \& John Goldsmith (eds.), Autosegmental studies in Bantu tone, 105-182. Dordrecht: Foris.

Kiyomi, Setsuko and Stuart Davis. 1992. Verb Reduplication in SiSwati. African Languages and Cultures 5. 113-124.

Laughren, Mary. 1984. Tone in Zulu Nouns. In George Clements \& John Goldsmith (eds.), Autosegmental studies in Bantu tone, 183-234. Dordrecht: Foris.

Lombardi, Linda and John McCarthy. 1991. Prosodic circumscription in Choctaw morphology. Phonology 8. 37-72.

Maddieson, Ian. 1978. Universals of tone. In Joseph Greenberg (ed.), Universals of human language, vol. 2 phonology, 335-365. Stanford University Press.

Marantz, Alec. 1982. Re-reduplication. Linguistic Inquiry 13. 435-482.

Marantz, Alec. 1987. Phonologically induced bracketing paradoxes in full morpheme reduplication. Proceedings of the Sixth West Coast Conference on Formal Linguistics 203-212.

McCarthy, John. 2000. Faithfulness and prosodic circumscription. Ms., UMass-Amherst.

McCarthy, John and Alan Prince. 1995. Faithfulness and reduplicative identity. University of Massachusetts Occasional Papers in Linguistics 18: Papers in Optimality Theory, 249-384. Amherst, MA: GLSA.

Mutaka, Ngessimo and Larry Hyman. 1990. Syllables and morpheme integrity in Kinande reduplication. Phonology 7. 73-120.

Myers, Scott. 1987. Tone and the structure of words in Shona. Amherst, MA: UMass-Amherst Ph.D. dissertation.

Myers, Scott. 1998. AUX in Bantu Morphology and Phonology. In Larry Hyman \& Charles Kisseberth (eds.), Theoretical Aspects of Bantu Tone, 231-264. Stanford, CA: CSLI.

Odden, David. 1993. Interaction between modules in Lexical Phonology. In Sharon Hargus and Ellen Kaisse (eds.), Phonetics and phonology 4: Studies in Lexical Phonology, 111-144. San Diego, CA: Academic Press.

Odden, David. 1996. Patterns of Reduplication in Kikerewe. OSU Working Papers in Linguistics 48. 111-149.

Odden, David and Mary Odden. 1985. Ordered reduplication in Kíhehe. Linguistic Inquiry 16. 497-503.

Pulleyblank, Doug. 1986. Tone in Lexical Phonology. Dordrecht: Reidel.

Rackowski, Andrea. 1999. Morphological optionality in Tagalog aspectual reduplication. Papers on Morphology and Syntax, Cycle Two, MIT Working Papers in Linguistics 34. 107-136.

Rycroft, David. 1963. Tone in Zulu nouns. African Language Studies 4. 43-68.

Schadeberg Thilo. 2003. Derivation. In Derek Nurse \& Gérard Philippson (eds.), The Bantu languages, 71-89. New York: Routledge.

Sibanda, Galen. 2004. Verbal Phonology and Morphology of Ndebele. Berkeley, CA: UCBerkeley dissertation.

Van der Spuy, Andrew. 1993. Dislocated noun phrases in Nguni. Lingua 90(4). 335-355.

Toni Cook tcook2@uvm.edu
Submitted: 22 July 2015

Accepted: 10 November 2015

Revisions: 22 July 2016 